\title{
Diurnal timing of nonmigratory movement by birds: the importance of
}

\section{foraging spatial scales ${ }^{a}$}

Julie M. Mallon', Marlee Tucker ${ }^{2,3,4}$, Annalea Beard ${ }^{5}$, Richard O. Bierregaard Jr. ${ }^{6}$, Keith L. Bildstein ${ }^{7}$, Katrin Böhning-Gaese ${ }^{2,3}$, John N. Brzorad ${ }^{8}$, Evan R. Buechley ${ }^{9,10}$, Javier Bustamante ${ }^{11,12}$, Carlos Carrapato $^{13}$, José Alfredo Castillo-Guerrero ${ }^{14}$, Elizabeth Clingham ${ }^{15}$, Mark Desholm ${ }^{16}$, Christopher R. DeSorbo $^{17}$, Robert Domenech ${ }^{18}$, Hayley Douglas ${ }^{19}$, Olivier Duriez ${ }^{20}$, Peter Enggist ${ }^{21}$, Nina Farwig ${ }^{22}$, Wolfgang Fiedler ${ }^{23,24}$, Anna Gagliardo ${ }^{25}$, Clara García-Ripollés ${ }^{26}$, José Antonio Gil Gallús ${ }^{27}$, Morgan E. Gilmour $^{28,29}$, Roi Harel ${ }^{30}$, Autumn-Lynn Harrison ${ }^{31}$, Leeann Henry ${ }^{32}$, Todd E. Katzner ${ }^{33}$, Roland Kays ${ }^{34,35}$, Erik Kleyheeg $^{23,36}$, Rubén Limiñana ${ }^{37,38}$, Pascual López-López ${ }^{39}$, Giuseppe Lucia ${ }^{40}$, Alan Maccarone, Egidio Mallia $^{41}$, Ugo Mellone ${ }^{40,42}$, Elizabeth K. Mojica ${ }^{43,44}$, Ran Nathan ${ }^{30}$, Scott H. Newman ${ }^{45}$, Steffen Oppel $^{46}$, Yotam Orchan ${ }^{30}$, Diann J. Prosser ${ }^{47}$, Hannah Riley ${ }^{19}$, Sascha Rösner ${ }^{22,48}$, Dana G. Schabo ${ }^{22}$, Holger Schulz ${ }^{21,49}$, Scott Shaffer ${ }^{50}$, Adam Shreading ${ }^{18}$, João Paulo Silva ${ }^{51,52}$, Jolene Sim ${ }^{53}$, Henrik Skov $^{54}$, Orr Spiegel ${ }^{55}$, Matthew J. Stuber ${ }^{56}$, John Y. Takekawa ${ }^{57}$, Vicente Urios ${ }^{42}$, Javier Vidal-Mateo ${ }^{42}$, Kevin Warner ${ }^{58}$, Bryan D. Watts ${ }^{43}$, Nicola Weber ${ }^{53,59}$, Sam Weber ${ }^{53,59}$, Martin Wikelski ${ }^{23,24,60}$, Ramunas Žydelis $^{61}$, Thomas Mueller ${ }^{2,3}$, William F. Fagan ${ }^{1}$

${ }^{1}$ Department of Biology, University of Maryland, College Park, MD, 20742, USA

${ }^{2}$ Senckenberg Biodiversity and Climate Research Centre, Senckenberg Gesellschaft für Naturforschung, Senckenberganlage 25, 60325 Frankfurt (Main), Germany

${ }^{3}$ Department of Biological Sciences, Goethe University, Max-von-Laue-Straße 9, 60438, 30 Frankfurt (Main), Germany

Department of Environmental Science, Institute for Wetland and Water Research, Radboud University, P.O. Box 9010, NL-6500 GL, Nijmegen, The Netherlands

${ }^{5}$ School of Biosciences, Sir Martin Evans Building, Cardiff University, Cardiff, Wales, CF10 3AX, UK

${ }^{6}$ Biology Department, University of North Carolina at Charlotte, 9201 University City Boulevard, Charlotte, NC 28223 USA

${ }^{7}$ Hawk Mountain Sanctuary, Acopian Center for Conservation Learning, 410 Summer Valley Road, Orwigsburg, PA 17961, USA

${ }^{8}$ Reese Institute for Conservation of Natural Resources, Lenoir-Rhyne University, Hickory, North Carolina, 28601, USA

${ }^{9}$ HawkWatch International, 2240 South 900 East, Salt Lake City, UT 84106, USA

${ }^{10}$ Biodiversity and Conservation Ecology Lab, University of Utah, 257 South 1400 East, Salt Lake City, UT 84112, USA

${ }^{11}$ Department of Wetland Ecology, Estación Biológica de Doñana (CSIC), C/Américo Vespucio 26, 41092, Sevilla, Spain

${ }^{12}$ Remote Sensing and GIS Lab (LAST-EBD), Estación Biológica de Doñana (CSIC), C/Américo

Vespucio 26, Isla de la Cartuja, Sevilla 41092, Spain

${ }^{13}$ Instituto da Conservação da Natureza e das Florestas, Parque Natural do Vale do Guadiana, Centro

Polivalente de Divulgação da Casa do Lanternim, Rua D. Sancho II, no 15 | 7750-350 Mértola, Portugal

${ }^{14}$ Departamento de Estudios para el Desarrollo Sustentable de Zona Costera, Centro Universitario de la ssta Sur, Universidad de Guadalajara. Gómez Farías, Núm. 82, C.P. 48980, San Patricio-Melaque,

Cihuatlán, Jalisco, México

${ }^{15}$ Foreign and Commonwealth Office, The Castle, Jamestown, St Helena Island, South Atlantic Ocean, STHL 1ZZ, UK

${ }^{16}$ BirdLife Denmark, Vesterbrogade 140, 1620 Copenhagen V, Denmark

${ }^{17}$ Biodiversity Research Institute, 276 Canco Rd, Portland, ME 04103, USA

${ }^{18}$ Raptor View Research Institute, P.O. Box 4323, Missoula, MT 59806, USA

${ }^{19}$ Tag-n-Track Clyde Muirshiel Regional Park, Lochlip Road, Lochwinnoch, Renfrewshire PA12 4EA, Scotland

${ }^{20}$ Centre d'Ecologie Fonctionnelle et Evolutive, UMR 5175, CNRS - Université de Montpellier -

Université Paul-Valéry Montpellier - EPHE, 1919 route de Mende, 34293 Montpellier, France

${ }^{21}$ Storch Schweiz, Bergstrasse 46, 8280 Kreuzlingen, Switzerland

${ }^{22}$ Conservation Ecology, Department of Biology, Philipps-University Marburg, Karl-von-Frisch Str. 8,

Marburg 35043, Germany

${ }^{23}$ Department of Migration, Max Planck Institute of Animal Behavior, 78315 Radolfzell, Germany

${ }^{24}$ Department of Biology, University of Konstanz, Konstanz, Germany

${ }^{25}$ Department of Biology, University of Pisa, Via Volta 6, 56126 Pisa, Italy 
${ }^{26}$ Environment Science and Solutions S.L., Plaza Jesús de Medinaceli 6 - 14, 46024, Valencia, Spain

${ }^{27}$ Fundación para la Conversación del Quebrantahuesos (FCQ), Plaza San Pedro Nolasco 1, 4-F 50.001 Zaragoza, Spain

${ }^{28}$ Ocean Sciences Department, University of California, Santa Cruz, Santa Cruz, California, 95060 USA

${ }^{29}$ Institute for Marine and Antarctic Studies, University of Tasmania, Newnham Tasmania 7250 Australia

${ }^{30}$ Movement Ecology Laboratory, Department of Ecology, Evolution and Behavior, Alexander Silberman Institute of Life Sciences, The Hebrew University of Jerusalem, Edmond J. Safra Campus, Jerusalem 91904, Israel

${ }^{31}$ Migratory Bird Center, Smithsonian Conservation Biology Institute, National Zoological Park, Washington, DC 20008, USA

${ }^{32}$ Environmental Management Directorate - Marine Section, St Helena Government, Jamestown, St Helena, STHL 1ZZ, South Atlantic

${ }^{33}$ US Geological Survey, Forest and Rangeland Ecosystem Science Center, Boise, ID, 83706, USA

${ }^{34}$ North Carolina Museum of Natural Sciences, 11 West Jone St., Raleigh NC 27601, USA

${ }^{35}$ Department Forestry and Environmental Resources, North Carolina State University, Raleigh, NC 27695, USA

${ }^{36}$ Ecology \& Biodiversity Group, Institute of Environmental Biology, Utrecht University, Utrecht, The Netherlands

${ }^{37}$ Departamento de Didáctica General y Didácticas Específicas, University of Alicante, E-03080 Alicante, Spain

${ }^{38}$ Instituto Universitario de Física Aplicada a las Ciencias y la Tecnología (IUFACyT), University of

Alicante, Alicante, Spain

${ }^{39}$ University of Valencia, Cavanilles Institute of Biodiversity and Evolutionary Biology, Terrestrial

Vertebrates Group, C/ Catedrático José Beltran 2, E-46980 Paterna, Valencia, Spain

${ }^{40}$ MEDRAPTORS (Mediterranean Raptor Migration Network), Via Mario Fioretti 18, 00152 Rome, Italy

${ }^{41}$ Parco Gallipoli Cognato Piccole Dolomiti Lucane, Localita Palazzo, Accettura IT75011, Italy

${ }^{42}$ Vertebrates Zoology Research Group, University of Alicante, E-03080, Alicante, Spain

${ }^{43}$ Center for Conservation Biology, College of William and Mary and Virginia Commonwealth University, Williamsburg, VA, USA

${ }^{44}$ EDM International, Inc., Fort Collins, Colorado, USA

${ }^{45}$ Food and Agriculture Organization of the United Nations, Regional Office for Africa, Accra Ghana

${ }^{46}$ RSPB Centre for Conservation Science, Royal Society for the Protection of Birds, The David

Attenborough Building, Pembroke Street, Cambridge CB2 3QZ, UK

${ }^{47}$ US Geological Survey, Patuxent Wildlife Research Center, Laurel, MD 20708, USA

${ }^{48}$ pixeldiversity GmbH, Kirchweg 2, 35043 Marburg, Germany

${ }^{49}$ Schulz Wildlife Consulting, Lüttensee 15, 24861 Bergenhusen, Germany

${ }^{50}$ Centre for Ecology, Evolution and Environmental Changes; Faculdade de Ciências da Universidade de Lisboa, Campo Grande, 1749-016 Lisbon, Portugal

${ }^{51} \mathrm{CIBIO} / \mathrm{InBIO}$, Centro de Investigação em Biodiversidade e Recursos Genéticos, Laboratório

Associado, Universidade do Porto, Campus Agrário de Vairão, 4485-661 Vairão, Portugal

${ }^{52} \mathrm{CIBIO} / \mathrm{InBIO}$, Centro de Investigação em Biodiversidade e Recursos Genéticos, Laboratório

Associado, Instituto Superior de Agronomia, Universidade de Lisboa, Tapada da Ajuda, 1349-017

Lisboa, Portugal

${ }^{53}$ Ascension Island Government Conservation Department, Georgetown, Ascension Island, South

Atlantic, ASCN 1ZZ, South Atlantic

${ }^{54}$ Ecology and Environment Department, DHI, Hørsholm, Denmark

School of Zoology, Faculty of Life Sciences, Tel Aviv University, Tel Aviv 69978, Israel

${ }^{56}$ U.S. Fish and Wildlife Service; Migratory Birds and Habitat Program; Portland, OR 97232, USA

${ }^{57}$ U.S. Geological Survey, Western Ecological Research Center, San Francisco Bay Estuary Field Station, 505 Azuar Drive, Vallejo, CA 94592, USA

${ }^{58}$ Environmental Management Office, Idaho Army National Guard, Boise, Idaho 83705, USA

${ }^{59}$ Centre for Ecology and Conservation, College of Life and Environmental Sciences, University of Exeter, UK

${ }^{60}$ Centre for the Advanced Study of Collective Behaviour, University of Konstanz, 78457 Konstanz, Germany

${ }^{61}$ Ornitela UAB, Vilnius, Lithuania

${ }^{a}$ This draft manuscript is distributed solely for purposes of scientific peer review. Its content is deliberative and pre-decisional, so it must not be disclosed or released by reviewers. Because the manuscript has not yet been approved for publication by the U.S. Geological Survey (USGS), it does not represent any official USGS finding or policy. 
Corresponding author: Julie M Mallon, Department of Biology, University of Maryland, College Park, MD, 20742, USA. E-mail: jmmallon@umd.edu

Decision date: 09-Oct-2020

This article has been accepted for publication and undergone full peer review but has not been through the copyediting, typesetting, pagination and proofreading process, which may lead to differences between this version and the Version of Record. Please cite this article as doi: [10.1111/jav.02612].

'This article is protected by copyright. All rights reserved.' 


\section{Abstract}

Timing of activity can reveal an organism's efforts to optimize foraging either by minimizing energy loss through passive movement or by maximizing energetic gain through foraging. Here, we assess whether signals of either of these strategies are detectable in the timing of activity of daily, local movements by birds. We compare the similarities of timing of movement activity among species using six temporal variables: start of activity relative to sunrise, end of activity relative to sunset, relative speed at midday, number of movement bouts, bout duration, and proportion of active daytime hours. We test for the influence of flight mode and foraging habitat on the timing of movement activity across avian guilds. We used 64570 days of GPS movement data collected between 2002 and 2019 for local (non-migratory) movements of 991 birds from 49 species, representing 14 orders. Dissimilarity among daily activity patterns was best explained by flight mode. Terrestrial soaring birds began activity later and stopped activity earlier than pelagic soaring or flapping birds. Broad-scale foraging habitat explained less of the clustering patterns because of divergent timing of active periods of pelagic surface and diving foragers. Among pelagic birds, surface foragers were active throughout the day while diving foragers matched their active hours more closely to daylight hours. Pelagic surface foragers also had the greatest daily foraging distances, which was consistent with their daytime activity patterns. This study demonstrates that flight mode and foraging habitat influence temporal patterns of daily movement activity of birds.

Keywords: temporal, movement ecology, nonmigratory, multispecies, flight mode, foraging

'This article is protected by copyright. All rights reserved.' 


\section{Introduction}

An animal's movement behavior is heavily influenced by its evolutionary history, which affects movement capacity and behavior (Norberg and Norberg 1988, Tobalske 2001). An animal's movement path is based, in part, on the distribution of resources (Fryxell et al. 2004), which is determined by their environment. These interact when animals forage, as they need to traverse the landscape according to their movement capacities to locate resources distributed non-randomly in the environment (Suryan et al. 2008). To maximize energetic gains from foraging, the timing of an animal's foraging movements is expected to correspond to either the temporal availability of its resources (Rydell et al. 1996, Lang et al. 2018) or the quantity and quality of resources required (Jetz et al. 2004, Ramesh et al. 2015, Cid et al. 2020). Alternatively, animals can reduce their energy expenditure by timing their foraging activity when their movements are most energetically efficient (Chapman et al. 2011, Shepard et al. 2013) via behavioral thermoregulation (Matern et al. 2000) and passive movement (Krupczynski and Schuster 2008). Both strategies are used by animals to forage optimally (Stephens and Krebs 1986), but these strategies have yet to be evaluated together within any group of animals.

Birds are distinct from other vertebrates because most birds are volant and most fly actively (i.e., by flapping) while a smaller number fly passively (i.e., by soaring). Soaring birds save energy by using updrafts (Baudinette and Schmidt-Nielsen 1974) to move across the landscape. One tradeoff faced by terrestrial soaring birds is that the availability of updrafts is skewed towards daylight hours (Dennycuick 1978). Switching to flapping flight can further extend the activity of soaring birds (Stark and Liechti 1993, Harel et al. 2016) as flapping flight is self-powered and can therefore be used in a broader suite of conditions.

When animals can be flexible in the timing of their movements, their activity is expected to be driven more by ecological interactions and the need to acquire resources. These needs can manifest as temporal matching between consumers and their resources. For example, Black-legged Kittiwakes (Rissa

'This article is protected by copyright. All rights reserved.' 
tridactyla) time their foraging concurrently with tidal cycles, when prey are most accessible (Irons 1998). Alternatively, the amount of movement activity may be due to resource quality. When high quality food items are available, animals can spend more time resting as their energetic needs are met more quickly (Saj et al. 1999, Fleischer Jr et al. 2003, Ménard et al. 2013). Despite long lasting interest in the factors that shape animal activity times, it is still poorly understood how internal traits and external conditions jointly shape the timing of movement across avian species.

Using daily movement activity data from a wide range of avian species, we tested for broad-scale differences in the temporal patterns by flight mode and foraging habitat. Temporal patterns do not only describe when individuals are moving, but they also convey information about the behaviors driving those movements (Pasquaretta et al. 2020). Therefore, temporal patterns of movement activity are best described using a suite of variables. First, we evaluated the similarity of temporal patterns among species using multivariate analyses and test for signals of foraging habitat and flight mode among clusters of species in ordinal space. Due to geographic and dietary segregation, we expected to find the greatest differences in multivariate space to be between birds from terrestrial and pelagic foraging habitats.

Second, we hypothesized that the timing of daily movement activity is more restricted for species that soar, because the flight performance of soaring birds varies within a day (Mellone et al. 2012) due to temporal variation in 
availability of environmentally derived updrafts (Spiegel et al. 2013). We predicted start and end times of movement activities would differ between flight modes. Flapping birds are unrestricted in their capacity to move and therefore can be active before sunrise and after sunset; in contrast, we expected terrestrial soaring birds to be limited to daylight hours. Soaring flight is most beneficial for large-bodied birds (Hedenström 1993), which are often raptorial (Schoener 1968); consequently, the use of soaring flight covaries with trophic level and morphology (Viscor and Fuster 1987, Baliga et al. 2019). We also predicted that pelagic soaring birds would be less temporally restricted than non-soaring birds as dynamic soaring is not driven directly by solar energy but by wind and wave energy (Pennycuick 1982).

Material and Methods

Data

We compiled GPS tracking data for 49 bird species whose movements were studied between 2002 and 2019. We obtained data from Movebank (www.movebank.org; Wikelski and Kays 2018) or through direct contributions by co-authors (Supplementary material Appendix 1). For quality control, we removed anomalous locations with speeds greater than $80 \mathrm{kmh}^{-1}$ for flapping species and locations with speeds greater than 100 $\mathrm{kmh}^{-1}$ for soaring species. All speeds were calculated as the speed between points. We calculated UTM zones from coordinates. To evaluate the timing of 
movement relative to local sunrise and sunset, all timestamps were converted from GMT to local time.

\section{Our dataset included movements from 49 species (Supplementary material} Appendix 1). These species represent 14 orders: Accipitriformes, Anseriformes, Bucerotiformes, Charadriiformes, Ciconiiformes, Falconiformes, Gruiformes, Otidiformes, Passeriformes, Pelecaniformes, Phaethontiformes, Phoenicopteriformes, Procellariiformes, and Suliformes. Most $(n=46)$ species were non-Passeriformes, and all Passeriformes were from the same genus (Corvus).

We analyzed movement data at the daily scale. Most of the data were sampled at hourly time intervals, so we subsampled high resolution data to an hourly scale with location intervals $\geq 57$ min (mean time between locations: $79.5+/-31.1 \mathrm{~min}$ ). To accurately assess active and inactive states while maximizing number of sampling days, we excluded sampling intervals $\geq 180 \mathrm{~min}$. We did not interpolate missing points.

Days included in the analysis had a minimum of eight locations per day. We selected eight-hour minimum time periods to represent the daily scale because many telemetry units do not sample continuously and, instead, cycle on and off to save battery life. To avoid any potential bias in ovements due to handling during tagging, we excluded the first day of tracking for all studies. We included species with at least 20 days of data. Full sampling information is provided in Supplementary material (Appendix 1).

Due to known intra-specific differences that occur in association with migration (Cagnacci et al. 2016), our analyses explore non-migratory daily foraging movements. To compare local, foraging movements of birds, we standardized the data to include only non-migratory movements by excluding migrations from individuals with range shifts $>500 \mathrm{~km}$. We intentionally selected a high

'This article is protected by copyright. All rights reserved.' 
threshold to avoid removing exploratory and foraging movements by individuals that did not migrate in partially migratory populations.

\section{Movement characteristics}

Measurement errors due to error in calculations of latitude and longitude by global positioning system (GPS) are inherent in movement tracking studies (Frair et al. 2010) and can inflate estimates of movement activity. After comparing the distributions of location errors across species, we characterized locations as either 'active' or 'inactive' according to their mean speed. Species with a mean speed $<9 \mathrm{kmh}^{-1}$ had an activity threshold of $50 \mathrm{mh}^{-1}$. This threshold was conservative relative to the distributions of mean location errors across most of the species (Supplementary material Appendix 2). Species with a mean speed $>9 \mathrm{kmh}^{-1}$ had an activity threshold of $300 \mathrm{mh}^{-1}$.

These different thresholds allowed us to identify active versus inactive periods for terrestrial and pelagic birds, which forage at different spatial scales (Schoener 1968, Oppel et al. 2018). To confirm our results were not sensitive to spatial scale, we compared our results using a smaller threshold $\left(25 \mathrm{mh}^{-1}\right)$ and found no difference in the change in activity levels (Supplementary material Appendix 2). To determine if the sampling frequency affected the activity patterns of any groups of species, we compared our results to a 20 min sampling scheme. The differences between these two sampling schemes were linear; our results are therefore robust to temporal sampling (Supplementary material Appendix 2).

Based on these daily, active hours, we summarized temporal characteristics of daily movements using six variables, defined in Table 1 . The objective of these measures was not to reliably estimate species averages for these temporal variables, but to provide standard, relative measures that could allow for multispecies comparisons. We included the timing of activity relative to sunrise and sunset to understand the relationship between activity 
and light availability, while accounting for variation in latitudes and time of year across datasets. Several sampling regimes were set to collect data between sunrise and sunset, which limit our interpretations. However, these intervals were selected by experts on the focal species' biology, so we do not expect that the true mean start and end times of activity would differ strongly from our results. We list species with limited sampling periods (i.e., mean start or end of sampling time were within the hour of local sunrise and sunset) in Supplementary material Appendix 2. The distributions of the timing of movement activity for each species are reported in Supplementary material Appendix 3.

To determine if movements were clustered in time or dispersed throughout the day, we defined number of movement bouts as the number of groups of consecutive active hours. We used the duration of these groups of consecutive active hours to represent activity duration. To determine how active species are at midday, for each day we calculated relative speed, which is the speed at solar noon divided by their speed averaged across all active bouts. Last, to compare activity among species, we calculated the proportion of time birds were active during the day, which was the proportion of hours between sunrise and sunset where the individual exceeded the speed threshold. We calculated this metric using the number of hours during daytime, rather than hours during the full day, because species with limited sampling periods would have artificially high activity levels. We first calculated each temporal variable at the daily scale and then found the 
mean of each temporal variable at the species level (Supplementary material Appendix 1).

Morphological and ecological characteristics

Ecological characteristic data were taken from the Elton $\mathbf{1 . 0}$ database (Wilman et al. 2016), which broadly describes the feeding ecology of all extant bird species in terms of the percent contribution of diet items and of different foraging habitats. We combined variables that were redundant for the species in our dataset; Table 2 lists the variables used and how they were derived.

Foraging habitats were collapsed to five levels: above ground, ground, freshwater, pelagic surface, and pelagic diver. Similarly, several diet variables were collapsed to six levels: herbivore, frugivore, carnivore, piscivore, invertivore, and scavenger.

Flight mode was described as either flapping or soaring. Although many species may occasionally be observed soaring, we included only species that soar regularly. We further subdivided soaring into obligate, facultative, and pelagic soaring. All other species were categorized as flapping.

We gathered morphometric data for three variables: body mass $(\mathrm{kg})$, wing span $(\mathrm{m})$, and wing area $\left(m^{2}\right)$. Where wing area values were missing, but wing span was known, we calculated wing area using aspect ratio (wingspan ${ }^{2} /$ wingarea) from a closely related species. Then, using known wingspan and estimated aspect ratio, we were able to derive wing area and relative wing loading (Pennycuick 2008). Wing spans were unknown for two species (Anas poecilorhyncha and Grus 
nigricollis), which we excluded from the analyses of morphological characteristics. We controlled for the effect of body size by using relative wing loading $\left(\right.$ bodymass $^{2 / 3} /$ wingarea; Norberg and Norberg 1988). We used only relative wing loading and aspect ratio in our analyses. All species' morphological data and sources, as well as ecological character data, are provided in the Supplementary material (Appendix 4).

\section{Analysis}

To determine which guilds were most similar in the timing of movement activity, we quantified dissimilarity across the suite of temporal variables (listed in Table 1) using non-metric multidimensional scaling (NMDS). NMDS is a distance-based ordination that maximizes rank order correlation, which is suitable for non-parametric data. Accipitriformes and Anseriformes were overrepresented in our dataset, making our dataset phylogenetically uneven.

To correct for this, we bootstrapped our NMDS analysis by randomly subsampling four species (the median size of other orders with multiple individuals) within each order, iterated 100 times. For each iteration, we then tested for any significant diet, foraging, flight, and morphological correlates of the NMDS (Table 2). Our final analysis included only variables that were significant predictors for at least $20 \%$ of subsampled datasets. This allowed us to exclude any predictors that would have been significant only due to the skewedness of our dataset. As many behaviors and adaptations have coevolved, we also report any highly correlated predictors.

T) test our flight mode hypothesis, we used one-way ANOVAs followed by TukeyHSD post-hoc tests. We excluded one species that was an outlier with regards to daytime movement activity, Cory's shearwater (Calonectris diomedea), as our estimates of activity duration exceeded those of known activity budgets (Ramos et al. 2019). To explore the drivers of clustering among foraging habitats in ordinal space, we compared the distributions of active hours among foraging groups. To assess if the differences in activity level are due to physiological limitations of flight speed, we included a post-hoc analysis of the mean daily net squared displacement, a measurement of daily foraging distance, according to foraging habitat. Due to insufficient sample size, terrestrial above

'This article is protected by copyright. All rights reserved.' 
ground foragers were excluded from this analysis. We report summary statistics as mean and standard deviation. We performed analyses using R version 3.6.3 (2020-02-29) (R Core Team 2020); a list of R packages used can be found in the Supplementary material (Appendix 5).

Results

We summarized 64570 days of movement data for 991 birds. For three species, movement data came from fewer than three individuals

(Supplementary material Appendix 1). Wing spans ranged from 0.71 to $2.81 \mathrm{~m}$ and body mass ranged from 0.44 to $9.87 \mathrm{~kg}$, a range that includes the body masses of $\mathbf{2 8} \%$ of all volant non-Passeriformes.

We found several continuous covariates related to the clustering of species according to the suite of temporal variables. Variation along NMDS1 was largely attributed to terrestrial ground foragers and pelagic surface foragers (Figure 1a). Terrestrial ground foragers were largely comprised of Accipitriformes and were therefore correlated with obligate and facultative soaring birds, scavenging ( $r=0.63)$, and carnivorous diets $(r=0.71)$. Pelagic surface foragers were comprised of Procellariiformes and some Suliformes (i e., Frigatebirds), which were positively correlated with high aspect ratio wings $(r=0.76)$, pelagic soaring, and invertivores. However, there was no separation between terrestrial and pelagic foragers in ordinal space. The greatest separation between foraging groups was between pelagic diving and pelagic surface foragers (Figure 1b). Variation along NMDS2 was largely attributed to flapping versus soaring flight (Figure 1c). In our dataset, body 
size was related to flight mode (soaring $3.65 \pm 2.76 \mathrm{~kg}$, flapping $1.20 \pm 0.60$ kg).

Soaring birds had higher relative speeds than flapping birds at midday (soaring: $0.901 \pm 0.232$; flapping: $0.568 \pm 0.211 ; F=26.28, d f=1, p<0.001$ )

Obligate soaring birds began activity later than flapping birds (obligate soaring: $3.250 \pm 1.035 \mathrm{~h}$; flapping: $0.750 \pm 1.943 \mathrm{~h} ; \mathrm{F}=14.542, \mathrm{df}=3, p<$ 0.001; TukeyHSD $p=0.017$; Figure 2a). Similarly, obligate soaring birds stopped activity earlier than did flapping birds (obligate soaring: $-1.286 \pm$ $0.881 \mathrm{~h}$; flapping: $0.850 \pm 1.755 \mathrm{~h} ; \mathrm{F}=6.777, \mathrm{df}=3, \mathrm{p}<0.001$; TukeyHSD $p=$ 0.018; Figure $2 b$ ). The same pattern was observed for pelagic soaring birds. Obligate soaring birds began activity later than pelagic soaring birds (pelagic soaring: $-3.143 \pm 3.532 \mathrm{~h}$; TukeyHSD $p<0.001$; Figure $2 a$ ) and obligate soaring birds stopped activity earlier than pelagic soaring birds (pelagic soaring: $2.429 \pm 2.37 \mathrm{~h}$; TukeyHSD $p<0.001$; Figure $2 b$ ). Post-hoc tests did not reveal significant differences in the start or end times between obligate and facultative soaring birds (sunrise $p=0.159$, sunset $p=0.224$ ), but obligate soaring birds were active for a shorter range of hours in the day (Figure 2).

Activity distributions differed by foraging habitats (Figure 3a). Pelagic surface foragers were active most continuously throughout the day and terrestrial ground foragers had the narrowest range of active hours. Differences in the activity patterns of pelagic surface foragers and diving foragers corresponded to differences in daily foraging distances (Figure 3c). 
Daily maximum net squared displacement was greatest among pelagic surface foragers, indicating they travelled the furthest within a day of any foraging group $(F=3.373, \mathrm{df}=3, \mathrm{p}=0.027)$. These differences were not due to differences in mean flight speed (Figure 3b). Pelagic foragers had greater mean flight speeds than terrestrial foragers, but this was partially an artifact of our methods requiring different activity thresholds.

\section{Discussion}

In this study we have combined a rich GPS tracking data set, spanning over several species and guilds, and used a multispecies comparative approach to test for intrinsic factors that shape the timing of activity by birds. We found broad-scale differences in the timing of avian daily movement activity between flight modes, supporting our hypothesis. Movements of Accipitriformes, which represent the largest proportion of soaring birds in our broad dataset, were largely restricted to daytime hours. This effect was even stronger among obligate soaring birds (i.e. Old World and New World vultures). Soaring species were further differentiated from flapping species by higher relative speeds at midday. These findings were not surprising as updrafts are stronger around midday than in the morning or late afternoon, supporting previous research suggesting their activity is more strongly linked to the temporal availability of updrafts (Mandel and Bildstein 2007, Bildstein et al. 2009, Nathan et al. 2012, Sur et al. 2017) than to their spatial availability (Mallon et al. 2015).

Flapping species were characterized by a lower percent of activity during the day. This suggests either flapping species are less active than soaring species, or they are similarly active, but on different spatial scales. Flapping species were largely represented by Anseriformes (i.e., ducks and geese) and Pelecaniformes (i.e., herons), which forage locally (e.g. $<1$ km) by walking, stalking, dabbling, or grazing. These species generally feed on 
abundant or localized resources (i.e., herbivores and granivores), and therefore spend greater amounts of time foraging within a given area (Mueller and Fagan 2008).

Other species either face less temporal predictability of resources or have greater spatial heterogeneity of resources and are more mobile as a consequence (Mueller and Fagan 2008). This is true of soaring species, many of which use a fly-and-forage strategy where birds spend substantial time in flight searching for food over large spatial scales (e.g. 10's of kms; Ruxton and Houston 2004). This is consistent with other findings concerning foraging space use: large-bodied birds, which tend to feed on high-quality resources and forage over large spatial scales (Schoener 1968), travel farther in homogeneous environments than heterogeneous environments (Tucker et al. 2019). Among mammals, trophic level is correlated with home range size (Jetz et al. 2004), which is positively correlated with activity levels (Cid et al. 2020), suggesting a positive relationship between space use and activity levels over large scales.

Like our results for terrestrial species, the temporal patterns we observed of pelagic species are a consequence of the spatial scale they forage over. While flight mode is related to the same morphological adaptations that allow pelagic species to specialize as surface or diving foragers (Ashmole 1971), we argue instead that the differences in timing among pelagic birds are not aue to flight mode but to foraging behavior. In our dataset, pelagic surface foragers were comprised of Suliformes (i.e. boobies and frigatebirds) and Procellariiformes (i.e. albatrosses and shearwaters), which forage over different spatial scales (Oppel et al. 2018). Although in other colonies, Suliformes respond to intraspecific competition by traveling further from the colony to forage (Oppel et al. 2015), Suliformes in our dataset forage closer 
to their colonies relative to the Procellariiformes, which frequently forage in open ocean. This difference in space use also likely drives the observed differences in the temporal patterns of their movement activity. To travel further, but at similar flight speeds, Procellariiformes have longer foraging trips that often extend overnight. This resulted in Suliformes appearing to be relatively less active, as their foraging trips in our dataset were always $<24$ h. The predominantly diurnal activities of Suliformes contributed greatly to the overlap in temporal activity patterns between pelagic and terrestrial foragers. There was better contrast among pelagic birds when comparing foraging groups, as frigatebirds are not diving foragers like other Suliformes, but are surface foragers that behave more like Procellariiformes. Frigatebirds in our dataset did move at night but are diurnal foragers that sleep on the wing (Rattenborg et al. 2016). This, in part, explains why the differences in start times between pelagic surface and diving foragers were more distinct than between Procellariiformes and Suliformes alone.

At least for some species, the relative significance of flight mode and foraging habitat may not be clear cut. The timing of their movements may not be driven by food availability, but instead by foraging restrictions. For example, in arid climates, some birds reduce their activity during midday as a means of behavioral thermoregulation (Silva et al. 2015, Gudka et al. 2019). Likewise, visually orienting species are limited by the availability of light. As such, although fruits and seeds are available at all hours, Passerines begin activity at dawn when there is sufficient light to detect their food resources 


\section{(Roth and Lima 2007). Temporal segregation of foraging can also be driven by pressures to avoid predators or kleptoparasites (Baglione and Canestrari 2009), such as frigatebirds. Such adaptive behavior is thought to have contributed to the evolution of nocturnal foraging behaviors by some pelagic species (Hailman 1964).}

Interpretation of our results is limited as we compiled our dataset from several different studies, which were biased towards larger, data-rich species that can support the weight of telemetry units. Also, sampling schemes across studies were uneven in terms of inter-location frequency and effort; this required us to use data averaged at the species level. If our data could be resolved on the scales specific to each guild, rather than standardized across species, we might have identified other ecological variables, such as diet, as important drivers of movement activity. Nevertheless, our approach provided standardized activity metrics for 49 bird species, which allowed us to compare intrinsic drivers of movement activity across a diversity of avian guilds.

Although our analyses were restricted to temporal attributes of movement, the relationship between physiological limitations on flight speed and activity duration lead us to hypothesize that the spatial scales animals forage over is an important driver of the timing of movement activity. Our results show that animals have predictable, intrinsic patterns to the timing of local movements that make up the large-scale behaviors we are interested in studying. Recognizing that spatial scale indirectly influences the timing of movement activity, future studies that focus on the spatial attributes of animal movement should consider the temporal attributes of movement as well. For example, studying spatial and temporal patterns in concert may reveal intraspecific differences due to personality influences on movement behavior (Spiegel et al. 2017, Hertel et al. 2019). With the development of smaller, high-resolution tracking devices, future research may apply analyses such as ours to the full diversity of birds, filling gaps of our knowledge on granivorous, frugivorous and insectivorous species (e.g., passerines, shorebirds, swifts, etc.), which may reveal interesting new phylogenetic or allometric predictors of movement.

'This article is protected by copyright. All rights reserved.' 
Data Availability statement

$\mathbf{R}$ code used in analyses can be accessed at datadryad.com (insert doi here).

Most of the data used are publicly available at www.movebank.org.

\section{Conflict of interest - The authors declare no conflict of interest.}

\section{Authors Contributions}

JMM, MT, WFF, and TM conceived the ideas, designed methodology, and led the writing of the manuscript; JMM analyzed the data; AB, ROBJ, KLB, KBG, JNB, ERB, JB, CC, JACG, EC, MD, CRDS, RD, HD, OD, PE, NF, WF, AG, CGR, JAGG, MEG, RH, ALH, LH, RJ, TEK, RK, EK, RL, PLL, GL, AM, EM, UM, EKM, RN, SHN, YO, SO, DJP, HR, SR, DGS, HS, SS, AS, JPS, JS, HS, OS, MJS, JYT, VU, JVM, KW, BDW, NW, TM, WFF and RŽ collected the data. All authors contributed critically to the drafts and gave final approval for publication.

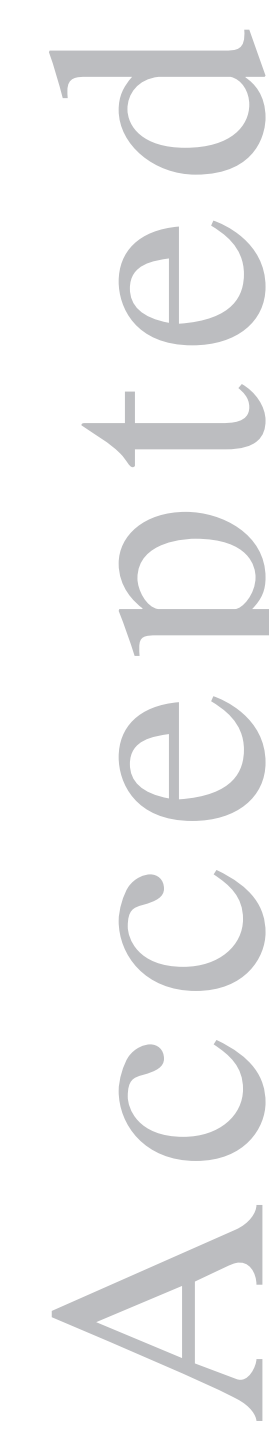

DECLARATIONS The findings and conclusions in this article are those of the author(s) and do not necessarily represent the views of the U.S. Fish and Wildlife Service. Any use of trade, product, or firm names is for descriptive purposes only and does not imply endorsement by the U.S. Government.

Ethics Statement: All analyses are based on pre-collected tracking datasets that were obtained under appropriate permits and were based on protocols approved by their respective institutions. Funding: We thank the Nature Conservancy, the Bailey Wildlife Foundation, the Bluestone Foundation, the Ocean View Foundation, Biodiversity Research Institute, the Maine Outdoor Heritage Fund, the Davis Conservation Foundation and The U.S. Department of Energy (DE-EE0005362), and the Darwin Initiative (19-026), EDP S.A. "Fundação para a Biodiversidade", and the Portuguese Foundation for Science and Technology (FCT) (DL57/2019/CP 1440/CT 0021), Enterprise St Helena (ESH), and Hawk Mountain Sanctuary for providing funding for the GPS data used in our analyses

"knowledgements: We would like to acknowledge Jose Manuel Lopez Vazquez, Steve Kirkland, Joseph Brandt, and Çağan $\mathrm{H}$. Şekercioğlu for assistance in accessing data. We would also like to acknowledge those that have contributed data: Missy Braham, Annette Broderick, Adam Duerr, Sharon Poessel, Annette Broderick, and Brendan Godley. We would like to thank Jesper Madsen, Anshuman Swain, Justin Calabrese, Elie Gurarie, and René Janssen for their helpful comments. We would also like to acknowledge all of those that helped during data collection, including Ezemvelo KZN Wildlife, VulPro, University of KwaZulu-Natal, Mike Neethling, Andy Ruffle, Cinereous vulture French National Action plan, Adriana Vallarino Moncada, Salvador HenandezVazquez, Abram Fleishman, Devyn Orr, Hillary Young, Stefan Kropidlowski, the US Fish and Wildlife Service, Secretaria de Marina, St Helena Nature Conservation Group (SNCG), the St Helena National Trust, the Terrestrial Conservation Section of the Environmental Management Division of St Helena Government, and others.

\footnotetext{
'This article is protected by copyright. All rights reserved.'
} 


\section{References}

Ashmole, N. P. 1971. Seabird ecology and the marine environment. - In: D. S Farner and J. R King (eds), Avian biology. Academic Press, New York, pp. 223- 286.

Baglione, V. and Canestrari, D. 2009. Kleptoparasitism and temporal segregation of sympatric corvids foraging in a refuse dump. - Auk 126: 566-578.

Baliga, V., Szabo, I. and Altshuler, D. 2019. Range of motion in the avian wing is strongly associated with flight behavior and body mass. - Sci. Adv. 5: eaaw6670.

Baudinette, R. and Schmidt-Nielsen, K. 1974. Energy cost of gliding flight in herring gulls. - Nature 248: 83.

Bildstein, K. L., Bechard, M. J., Farmer, C. and Newcomb, L. 2009. Narrow sea crossings present major obstacles to migrating griffon vultures gyps fulvus. - Ibis 151: 382-391.

Cagnacci, F., Focardi, S., Ghisla, A., Van Moorter, B., Merrill, E. H., Gurarie, E., Heurich, M., Mysterud, A., Linnell, J., Panzacchi, M. and others 2016. How many routes lead to migration? Comparison of methods to assess and characterize migratory movements. - J. Anim. Ecol. 85: 5468.

Chapman, J. W., Klaassen, R. H., Drake, V. A., Fossette, S., Hays, G. C., Metcalfe, J. D., Reynolds, A. M., Reynolds, D. R. and Alerstam, T. 2011. Animal orientation strategies for movement in flows. - Curr. Biol. 21: R861-R870.

Cid, B., Carbone, C., Fernandez, F. A., Jansen, P. A., Rowcliffe, J. M., O’Brien, T., Akampurira, E., Bitariho, R., Espinosa, S., Gajapersad, K. and others 2020. On the scaling of activity in tropical forest mammals. - Oikos 129: 668-676.

'This article is protected by copyright. All rights reserved.' 
Fleischer Jr, A. L., Bowman, R. and Woolfenden, G. E. 2003. Variation in foraging behavior, diet, and time of breeding of florida scrub-jays in suburban and wildland habitats. - Condor 105: 515527.

Frair, J. L., Fieberg, J., Hebblewhite, M., Cagnacci, F., DeCesare, N. J. and Pedrotti, L. 2010. Resolving issues of imprecise and habitat-biased locations in ecological analyses using gps telemetry data. - Philos. Trans. R. Soc. B 365: 2187-2200.

Fryxell, J. M., Wilmshurst, J. F. and Sinclair, A. R. 2004. Predictive models of movement by serengeti grazers. - Ecology 85: 2429-2435.

Gudka, M., Santos, C. D., Dolman, P. M., Abad-Gómez, J. M. and Silva, J. P. 2019. Feeling the heat: Elevated temperature affects male display activity of a lekking grassland bird. - PLoS One 14: e0221999.

Hailman, J. P. 1964. The Galapagos swallow-tailed gull is nocturnal. - Wilson Bull. 76: 347-354.

Harel, R., Horvitz, N. and Nathan, R. 2016. Adult vultures outperform juveniles in challenging thermal soaring conditions. - Sci. Rep. 6: 27865.

Hedenström, A. 1993. Migration by soaring or flapping flight in birds: The relative importance of energy cost and speed. - Philos. Trans. R. Soc. B 342: 353-361.

Hertel, A. G., Leclerc, M., Warren, D., Pelletier, F., Zedrosser, A. and Mueller, T. 2019. Don't poke Ine bear: Using tracking data to quantify behavioural syndromes in elusive wildlife. - Anim. Behav. 147: 91-104.

Irons, D. B. 1998. Foraging area fidelity of individual seabirds in relation to tidal cycles and flock feeding. - Ecology 79: 647-655.

Jetz, W., Carbone, C., Fulford, J. and Brown, J. H. 2004. The scaling of animal space use. Science 306: 266-268.

'This article is protected by copyright. All rights reserved.' 
Krupczynski, P. and Schuster, S. 2008. Fruit-catching fish tune their fast starts to compensate for drift. - Curr. Biol. 18: 1961-1965.

Lang, S. D., Mann, R. P. and Farine, D. R. 2018. Temporal activity patterns of predators and prey across broad geographic scales. - Behav. Ecol. 30: 172-180.

Mallon, J. M., Bildstein, K. L. and Katzner, T. E. 2015. In-flight turbulence benefits soaring birds. Auk 133: 79-85.

Mandel, J. T. and Bildstein, K. L. 2007. Turkey vultures use anthropogenic thermals to extend their daily activity period. - Wilson J. Ornithol. 119: 102-105.

Matern, S. A., Cech, J. J. and Hopkins, T. E. 2000. Diel movements of bat rays, myliobatis californica, in tomales bay, california: Evidence for behavioral thermoregulation? - Environ. Biol. Fishes 58: 173-182.

Mellone, U., Klaassen, R. H., Garc'ıa-Ripoll'es, C., Limiñana, R., L'opez-L'opez, P., Pav'on, D., Strandberg, R., Urios, V., Vardakis, M. and Alerstam, T. 2012. Interspecific comparison of the performance of soaring migrants in relation to morphology, meteorological conditions and migration strategies. - PLoS One 7: e39833.

Ménard, N., Motsch, P., Delahaye, A., Saintvanne, A., Le Flohic, G., Dupé, S., Vallet, D., Qarro, M. and Pierre, J.-S. 2013. Effect of habitat quality on the ecological behaviour of a temperate-living nrimate: Time-budget adjustments. - Primates 54:217-228.

Mueller, T. and Fagan, W. F. 2008. Search and navigation in dynamic environments-from individual behaviors to population distributions. - Oikos 117: 654-664.

Nathan, R., Spiegel, O., Fortmann-Roe, S., Harel, R., Wikelski, M. and Getz, W. M. 2012. Using triaxial acceleration data to identify behavioral modes of free-ranging animals: General concepts and tools illustrated for griffon vultures. - J. Exp. Biol. 215: 986-996.

'This article is protected by copyright. All rights reserved.' 
Norberg, U. and Norberg, R. 1988. Ecomorphology of flight and tree-trunk climbing in birds $(\mathrm{H}$ Ouellet, Ed.). - Proc. Int. Ornithol. Congr. 19: 2271-2282.

Oppel, S., Beard, A., Fox, D., Mackley, E., Leat, E., Henry, L., Clingham, E., Fowler, N., Sim, J., Sommerfeld, J. and others 2015. Foraging distribution of a tropical seabird supports ashmole's hypothesis of population regulation. - Behav. Ecol. Sociobiol. 69: 915-926.

Oppel, S., Bolton, M., Carneiro, A. P., Dias, M. P., Green, J. A., Masello, J. F., Phillips, R. A., Owen, E., Quillfeldt, P., Beard, A. and others 2018. Spatial scales of marine conservation management for breeding seabirds. - Mar. Policy 98: 37-46.

Pasquaretta, C., Dubois, T., Gomez-Moracho, T., Delepoulle, V. P., Le Loc'h, G., Heeb, P. and Lihoreau, M. 2020. Analysis of temporal patterns in animal movement networks. - Methods Ecol. Evol. 00: 1-13.

Pennycuick, C. 1978. Fifteen testable predictions about bird flight. - Oikos 30: 165-176.

Pennycuick, C. J. 1982. The flight of petrels and albatrosses (Procellariiformes), observed in south Georgia and its vicinity. - Philos. Trans. R. Soc. B 300: 75-106.

Pennycuick, C. 2008. Modelling the flying bird. - Elsevier.

Ramesh, T., Kalle, R., Sankar, K. and Qureshi, Q. 2015. Role of body size in activity budgets of mammals in the western ghats of India. - J. Trop. Ecol. 31: 315-323.

Ramos, R., Morera-Pujol, V., Cruz-Flores, M., López-Souto, S., Brothers, M. and González-Solís, J. 2019. A geolocator-tagged fledgling provides first evidence on juvenile movements of cory's shearwater Calonectris borealis. - Bird Study 66: 283-288.

Rattenborg, N. C., Voirin, B., Cruz, S. M., Tisdale, R., Dell'Omo, G., Lipp, H.-P., Wikelski, M. and Vyssotski, A. L. 2016. Evidence that birds sleep in mid-flight. - Nat. Commun. 7: 1-9.

'This article is protected by copyright. All rights reserved.' 
R Core Team 2020. R: A language and environment for statistical computing. - R Foundation for Statistical Computing.

Roth, T. C. and Lima, S. L. 2007. The predatory behavior of wintering accipiter hawks: Temporal patterns in activity of predators and prey. - Oecologia 152: 169-178.

Ruxton, G. D. and Houston, D. C. 2004. Obligate vertebrate scavengers must be large soaring fliers. - J Theor. Biol. 228: 431-436.

Rydell, J., Entwistle, A. and Racey, P. A. 1996. Timing of foraging flights of three species of bats in relation to insect activity and predation risk. - Oikos 76: 243-252.

Saj, T., Sicotte, P. and Paterson, J. D. 1999. Influence of human food consumption on the time budget of vervets. - Int. J. Primatol. 20: 977-994.

Schoener, T. W. 1968. Sizes of feeding territories among birds. - Ecology 49: 123-141.

Shepard, E. L., Wilson, R. P., Rees, W. G., Grundy, E., Lambertucci, S. A. and Vosper, S. B. 2013. Energy landscapes shape animal movement ecology. - Am. Nat. 182: 298-312.

Silva, J. P., Catry, I., Palmeirim, J. M. and Moreira, F. 2015. Freezing heat: Thermally imposed constraints on the daily activity patterns of a free-ranging grassland bird. - Ecosphere 6: 1-13.

Spiegel, O., Getz, W. M. and Nathan, R. 2013. Factors influencing foraging search efficiency: Why dn scarce lappet-faced vultures outperform ubiquitous white-backed vultures? - Am. Nat. 181: E102-E115.

Spiegel, O., Leu, S. T., Bull, C. M. and Sih, A. 2017. What's your move? Movement as a link between personality and spatial dynamics in animal populations. - Ecol. Lett. 20: 3-18.

Stark, H. and Liechti, F. 1993. Do levant sparrowhawks Accipiter brevipes also migrate at night? Ibis 135: 233-236.

'This article is protected by copyright. All rights reserved.' 
Stephens, D. W. and Krebs, J. R. 1986. Foraging theory. - Princeton Univ. Press.

Sur, M., Suffredini, T., Wessells, S. M., Bloom, P. H., Lanzone, M., Blackshire, S., Sridhar, S. and Katzner, T. 2017. Improved supervised classification of accelerometry data to distinguish behaviors of soaring birds. - PLoS One 12: e0174785.

Suryan, R. M., Anderson, D. J., Shaffer, S. A., Roby, D. D., Tremblay, Y., Costa, D. P., Sievert, P. R., Sato, F., Ozaki, K., Balogh, G. R. and others 2008. Wind, waves, and wing loading: Morphological specialization may limit range expansion of endangered albatrosses. - PLoS One 3: e4016.

Tobalske, B. W. 2001. Morphology, velocity, and intermittent flight in birds. - Am. Zool. 41: 177187.

Tucker, M. A., Alexandrou, O., Bierregaard Jr, R. O., Bildstein, K. L., Böhning-Gaese, K., Bracis, C., Brzorad, J. N., Buechley, E. R., Cabot, D., Calabrese, J. M. and others 2019. Large birds travel farther in homogeneous environments. - Global Ecol. Biogeogr. 28: 576-587.

Viscor, G. and Fuster, J. 1987. Relationships between morphological parameters in birds with different flying habits. - Comp. Biochem. Phys. A 87: 231-249.

Wikelski, M. and Kays, R. 2018. Movebank: Archive, analysis and sharing of animal movement data. - World Wide Web electronic publication.

vvilman, H., Belmaker, J., Simpson, J., de la Rosa, C., Rivadeneira, M. M. and Jetz, W. 2016.

EltonTraits 1.0: Species-level foraging attributes of the world's birds and mammals.

'This article is protected by copyright. All rights reserved.' 


\section{Figure Legends}

Figure 1: The NMDS ordination indicates inter-specific similarities within temporal activity patterns, among all 49 species. (a) NMDS annotated with environmental fit loadings (included if significant at $p$-value $<0.05$ ). Environmental fit loadings were bootstrapped to correct for an uneven sample across phylogeny. Ground foragers were correlated with carnivorous diets $(r=0.71)$ and scavenging diets $(r=0.63)$ and both were omitted from the environmental loadings for clarity. Pelagic surface foragers were correlated with high aspect ratio wings ( $r=0.76$ ), which was removed for clarity. NMDS annotated by (b) pelagic foraging habitats and (c) flight mode. Ellipses represent $90 \%$ confidence interval around the centroid of each group. (b) There is little overlap between the pelagic foraging groups, indicating that pelagic divers (purple) have different activity patterns than pelagic surface foragers (green). Terrestrial foragers (grey) had high overlap with pelagic foragers, indicating little differences between terrestrial and pelagic foragers, overall. (c) There is little overlap between flight modes, indicating that soaring species (light green) have different activity patterns than flapping species (blue). Stress value is 0.15

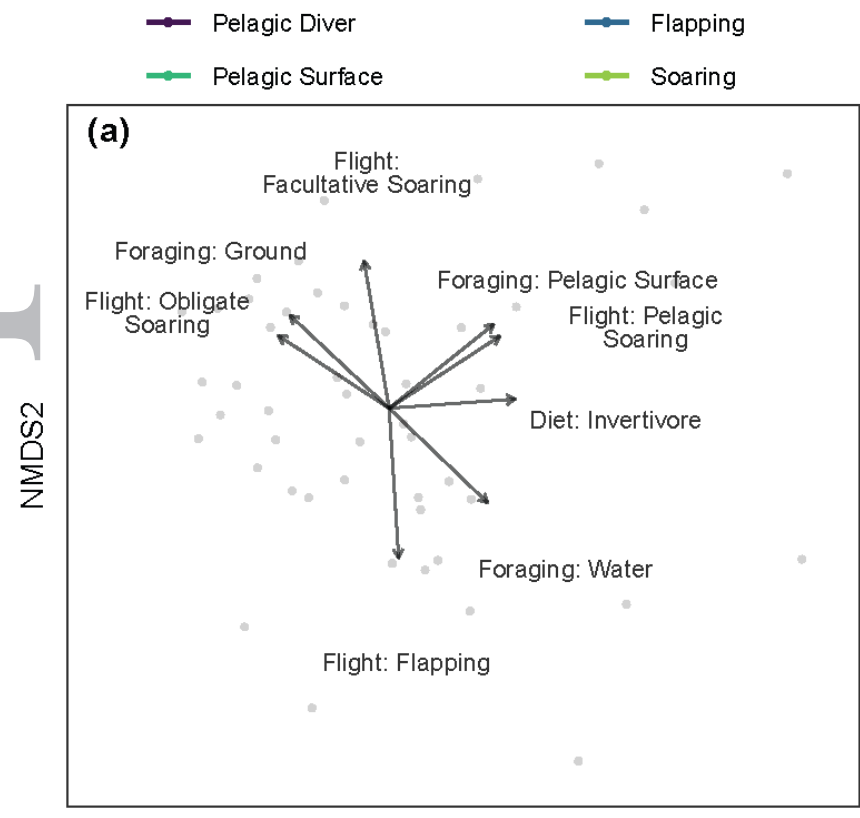

NMDS1
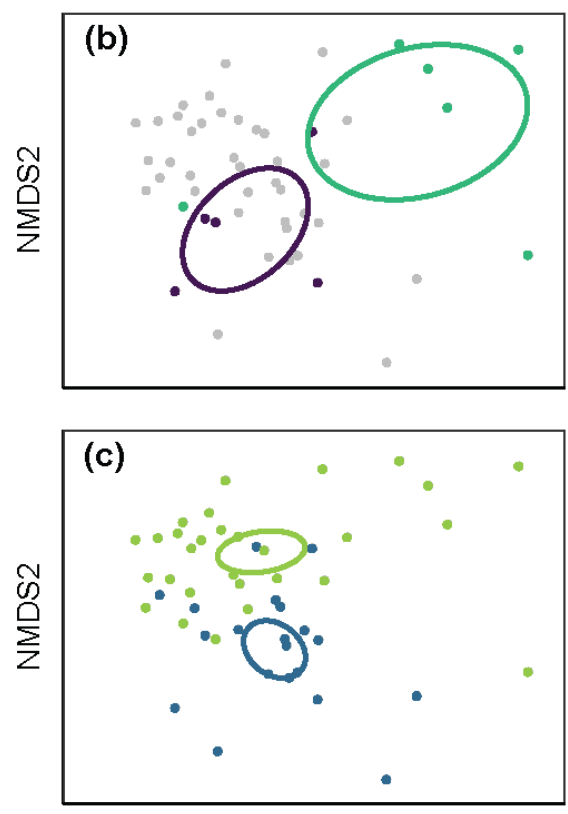

NMDS1 
Figure 2: Dot plots of flapping, terrestrial (obligate and facultative), and pelagic soaring birds by (a) start of activity relative to sunrise and (b) end of activity relative to sunset, with units in hours. (a) Terrestrial soaring birds began activity after sunrise, with obligate soaring birds beginning activity later than facultative soaring birds. (b) Terrestrial soaring birds ceased activity before or at sunset, with obligate soaring birds stopping activity earlier than facultative soaring birds. Sunrise and sunset times were similar for facultative soaring and flapping birds.
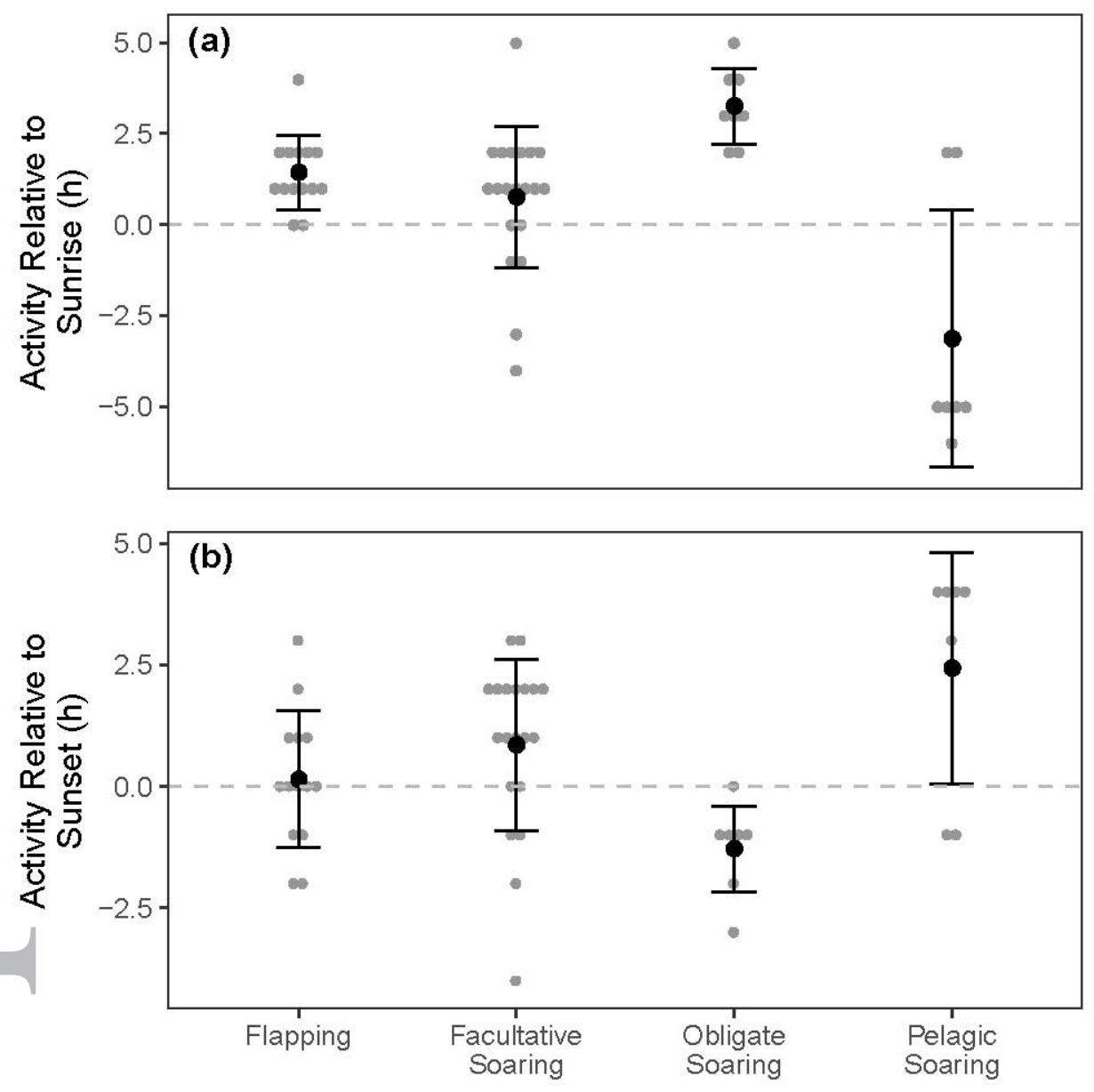
Figure 3: Foraging habitats by (a) active time, (b) mean speed, and (c) distance. For all plots, terrestrial above ground foragers were excluded due to small sample size $(n=2)$. (a) Distributions of active (black) and inactive (grey) hours by foraging habitat. Pelagic surface foragers were active a greater proportion of the day than pelagic diving and terrestrial foragers, whose activity was more clustered during midday. (b) Mean speed between points. There is no difference in maximum speeds among pelagic foraging habitats. (c) Post-hoc analyses of log-transformed squared net displacement (in meters) of daily foraging trips according to foraging habitat. Pelagic surface foragers travel farther than pelagic divers on daily foraging trips, suggesting differences in their activity levels is driven by their respective foraging distances.
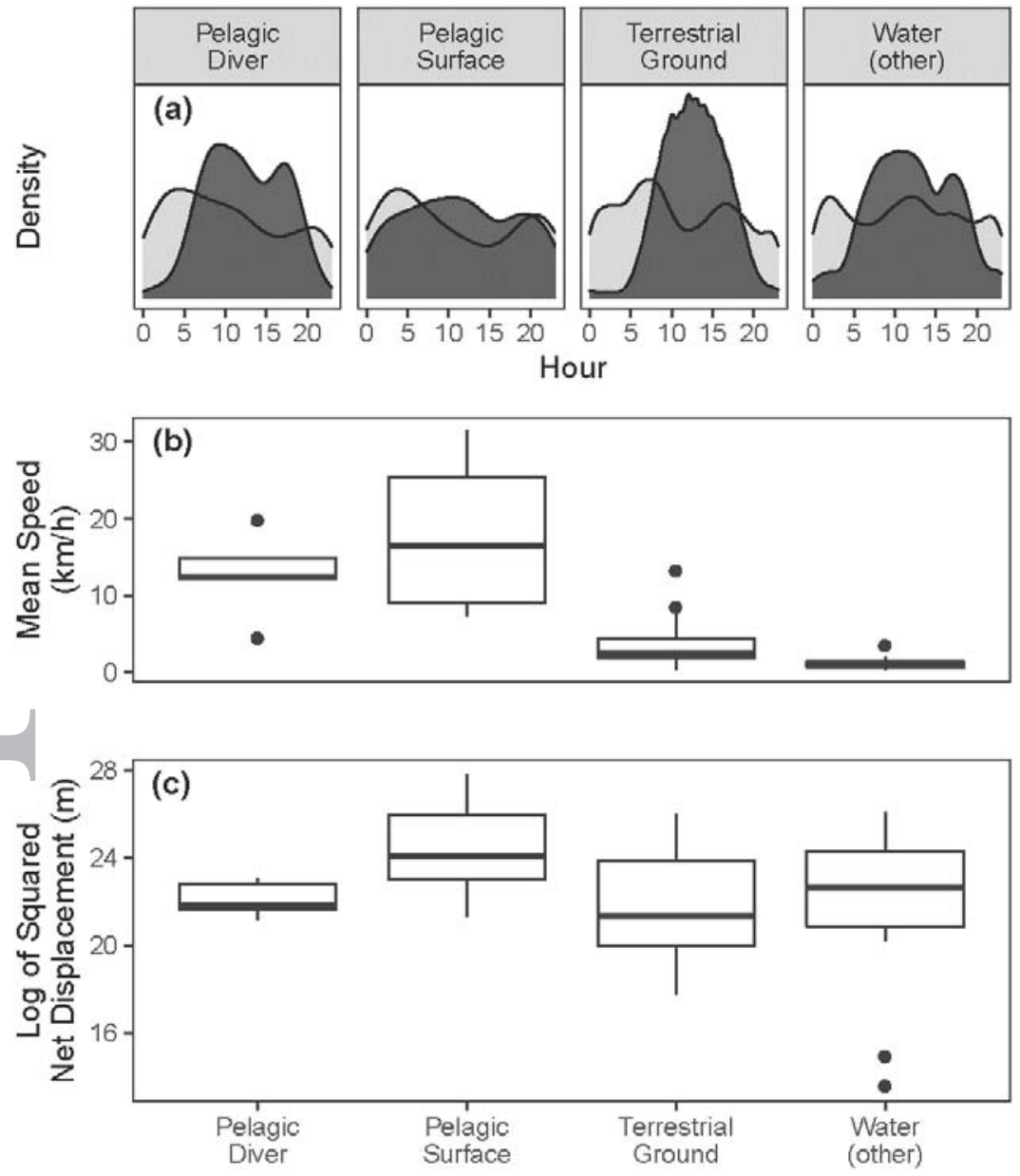
Table Legends

Table 1: Temporal variables and their definitions.

Variable Definition

Sunrise Activity

The time difference between first activity and sunrise

Sunset Activity

The time difference between last activity and sunset

Relative Speed at Speed at solar noon relative to mean speed Midday

Number of Movement Number of groups with $1+$ consecutive, active

Bouts hours

Activity Duration

The length of time between non-active locations

Proportion of Daytime Number of daytime active locations / total number Activity of daytime locations 
Table 2: Ecological variables used in analysis. Data sourced from Elton database (Wilman et al. 2016). Where variables are combined, sample sizes are indicated in parentheses. Final sample size used in analyses are in column $\mathbf{N}$.

Variable Category N Definition

Foraging Above $\quad 7$ midcanopy (6) + canopy (3) + aerial (6)

Habitat Ground

Ground $\quad 34$ ground (34) + understory (5)

Water (other) 29 freshwater or non-obligate pelagic species that forage below (4) + around surf (18)

Pelagic $\quad 7$ pelagic specialist that forage around surf

Surface

Pelagic Diver 8 pelagic specialist that forage below surf

Diet

Herbivore 17 plant (17) + seed (14)

Frugivore $\quad 6$ fruit

Carnivore 33 endotherms (18) + ectotherms (14) + unknown (4)

Piscivore $\quad 25$ fish

Invertivore $\quad 32$ invertebrates

Scavenger 20 carrion 
Flight Mode Pelagic 7 pelagic birds that soar $>\mathbf{2 0} \%$ of the time

Soaring

Obligate $\quad 8$ terrestrial birds that cannot sustain

Soaring flapping flight

Facultative $\quad 14$ terrestrial birds that soar $>20 \%$ of the time

Soaring

Flapping 20 birds that flap $>80 \%$ of the time 